\title{
Universal Health Coverage: Factoring Successful Economies
}

\author{
Prerna Bhasin ${ }^{1}$, Rakesh Bhardwaj ${ }^{2}$ \\ ${ }^{1}$ Inspire Analytics Ltd., London, UK \\ ${ }^{2}$ Department of Ophthalmology, Dr. Baba Saheb Ambedkar Hospital, Rohini, India \\ Email: prerna.bhasin@camh.ca
}

How to cite this paper: Bhasin, P. and Bhardwaj, R. (2018) Universal Health Coverage: Factoring Successful Economies. Health, 10, 1018-1030.

https://doi.org/10.4236/health.2018.107076

Received: April 26, 2018

Accepted: July 24, 2018

Published: July 27, 2018

Copyright $\odot 2018$ by authors and Scientific Research Publishing Inc. This work is licensed under the Creative Commons Attribution International License (CC BY 4.0).

http://creativecommons.org/licenses/by/4.0/

\section{(c) (i) Open Access}

\begin{abstract}
Countries are seeking to diversify sources of revenue for Universal Health Coverage (UHC), and strategies vary among countries at different stages on the road to UHC. The study tends to document these trade-offs by factoring successful economies across the globe. A review of peer-reviewed literature retrieved country-wise on the basis of successful UHC economies to establish the major factor associated with development of UHC. Political will has been recognized as one of the critical factors. Overcoming barriers associated with development of an adequate and sustainable financing mechanism and selecting the right package of services are other essential determinants. Reaching vulnerable groups and efficient use of resources were other factors that contributed to UHC development in Mexico and south-east Asian countries. UHC development is at threshold where nations should learn from one another, especially from those systems which appear to be doing better, and are more prepared to innovate, test and evaluate new approaches.
\end{abstract}

\section{Keywords}

UHC, Global, Equity, Health-Systems, Economies

\section{Introduction}

WHO's constitution of 1948 declared "health a fundamental human right" and the Alma-Ata declaration in 1978 reinstated "Health for AlP" agenda. With equity constitutionalised as the most important feature of health systems, universality has become the next core principle of an Integrated Health System. This means that countries need to track progress of national population and provide health benefits to all groups irrespective of sex, age, place of residence, migrant status and ethnic origin [1]. This quest gave rise to the concept of Universal 
Health Coverage (UHC). WHO defines it as a state where all people who need health services (prevention, promotion, treatment, rehabilitation, and palliative care) should be provided access to needed health services of sufficient quality, which are effective and without undue financial hardship [1] [2] [3] as seen in Table 1. It is often advocated as a way of improving health equity. The new paradigms of universal coverage or access embrace a wide range of health-related areas such as HIV/AIDS [4], reproductive health [5], health insurance [6], and free health services, particularly for women and children [3].

Universal health coverage has a direct impact on a population's health. It ensures access to health services and enables people to be more productive and active contributors to their families and communities. It provides financial risk protection by preventing out of pocket health expenditures. Universal health coverage thus, is a critical component of sustainable development and a key element of any effort to reduce social inequities [7]. UHC is increasingly being embraced at a global level as a priority in the post-2015 development agenda [8] as it seems to be the only available strategy to combat the paradoxical yet critical link between health, sustainable development and economic growth.

\section{Components of UHC}

The ideological foundation of UHC consists of three interrelated components: 1) the full spectrum of health services according to need; 2) financial protection from direct payment for health services when consumed; and 3) coverage for the entire population as shown in Figure 1 [9]. In the cube, UHC is conceived as a system that would progressively move towards complete coverage of a population, effective range of services and health financing. It was suggested that such a system requires a clear "provider-purchaser" split, where the issues of financing

Table 1. WHO's definition of universal health coverage [1].

The WHO states (verbatim):

"For a community or country to achieve universal health coverage, several factors must be in place, including:

1) A strong, efficient, well-run health system that meets priority health needs through people-centred integrated care (including services for HIV, tuberculosis, malaria, non-communicable diseases, maternal and child health) by:

- informing and encouraging people to stay healthy and prevent illness;

- detecting health conditions early;

- having the capacity to treat disease; and

- helping patients with rehabilitation

2) Affordability: a system for financing health services so people do not suffer financial hardship when using them. This can be achieved in a variety of ways.

3) Access to essential medicines and technologies to diagnose and treat medical problems.

4) A sufficient capacity of well-trained, motivated health workers to provide the services to meet patients" needs based on the best available evidence. 


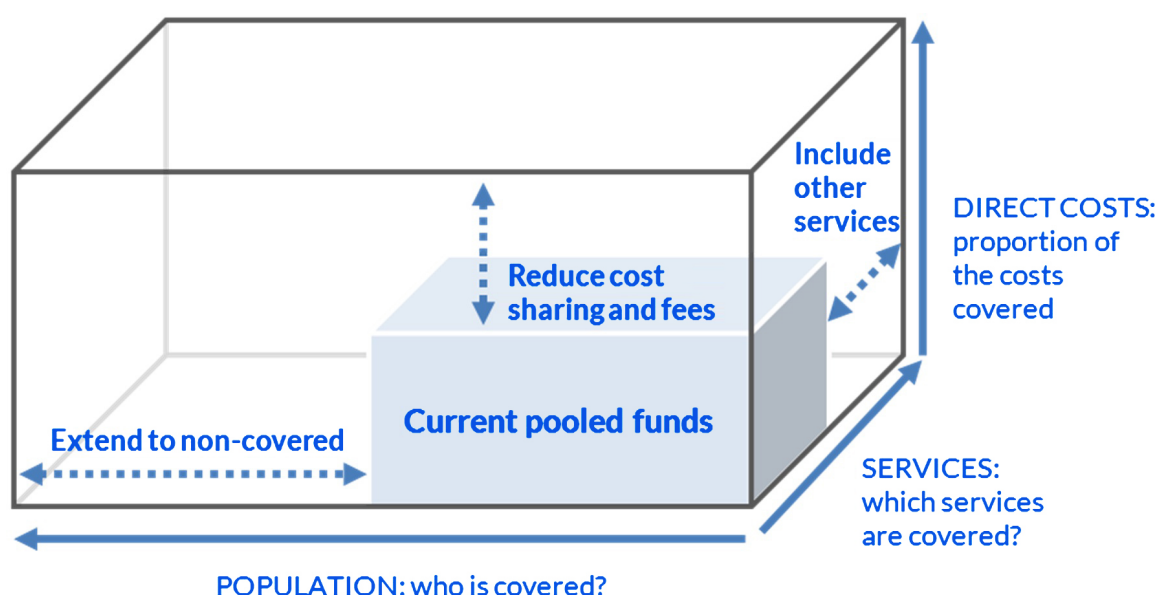

Three dimensions to consider when moving toward universal coverage.

Figure 1. The UHC cube [9]. The figure reflects three dimensions of coverage; population coverage, service coverage, and financial coverage or financial protection.

and management should be separated from provisioning [8]. With "state" as a manager, it can be concluded that, in theoretical terms UHC should not discriminate between public and private services, its only concerns are "cost-effectiveness" and "efficiency".

\section{Methodology}

Analysis of UHC has been conducted by many disciplines using a variety of methods, ranging from economics, sociology, political sciences, to public health. Of these traditions, we attempted to factor successful UHC economies and what made their healthcare system fruitful irrespective of main theoretical positions that have been previously identified to explain the expansion of health coverage. This article tends to describe main themes and determinants in the literature on UHC's successful implementation, drawing on illustrative examples of the leading paradigms of thought from various countries.

\section{How Were These Studies Chosen?}

This paper draws on the expertise of the health systems for countries where apparent progress has been made to provide universal health coverage. This is a rapid review of the health literature (grey and peer-reviewed articles). For published articles, both empirical and review, searches were conducted on PubMED and Google Scholar as well as specific journals focusing on positive impact of universal health coverage in various countries across the globe. The following key words were used for searches: "universal health coverage", "universal coverage", "health care financing", "health financing reforms", "insurance", "impact", "demand-side financing”, "health", "access", “equity”, "equality” and "efficiency". The search limits included all articles published since 2000 in English. The research strategy was borrowed from another work on UHC [10] [11] [12]. The 
study delineated following challenges that affect the coverage of UHC and has been Table 2.

\section{Results}

a) What Does It Take to Develop a UHC System?

Each country unravels its own unique path towards UHC, driven by its own history, politics, and existing health and financing structures. Therefore, though strategies that countries adopt to achieve UHC vary yet in planning their programs, countries typically weigh three dimensions of coverage expansion: who (breadth of cube-extent of the population covered), which services (depth of cube-proportion of services covered), and what proportion of costs will be covered (height of cube-extent of financial protection) of health coverage [13]. Country-specific contexts i.e. disease burden, health system, economic as well as political factors, will greatly influence the policy choices, but in spite of the varied approaches to achieving UHC, the following dimensions will apply across all contexts while making efficient trade-offs across these three dimensions [14].

\section{a1) Political Will and Economy}

As political scenario of a state is responsible for enabling or constraining social and economic reforms, political will has been recognized as one of the critical factors for UHC development. As UHC reforms intentionally redistribute resources in the health sector and across households, these policies inevitably involve political trade-offs and negotiations [2]. Therefore, political situations that can be responsible for adopting UHC goals; expanding health coverage; and reducing inequities in coverage [2] are of utmost importance in transitioning health systems.

a2) Where It Worked

Bangladesh and Ethiopia have emerged as clear examples of how social and political support can overcome macroeconomic constraints to realize their policy goal of adopting UHC. This has been recognised as an expression of national aspirations and as a means to mobilize efforts towards health reforms [15] [16].

Table 2. Challenges that affect the coverage of UHC [10] [11] [12].

1) Lack of political will and understanding of social determinants that undermine access for vulnerable and marginalized groups

2) Insufficient attention has been paid to the interaction of social determinants of health and health financing

3) There is an emphasis on equity, McKee and colleagues were of the opinion that some groups have higher health needs and lower financing capabilities than others; this implies the need for picking the right package for fitting the need of the population and increasing uptake with coverage.

4) The idea is find money, to understand how to mobilize the revenues to provide and sustain coverage; establishment of effective pooling and redistributive mechanisms to ensure equity and financial protection; and building of capacities to manage future expenditures as presented by Reich and co-workers. 
Ghana has established a national health insurance program as a platform for creating a unified risk pool through National Health Insurance Scheme, which integrated multiple community based plans under a single national program [13]; Indonesia and Vietnam also made significant leaps in integrating and harmonizing the multiple risk pools to achieve greater equity in coverage through economic integration [13] [17]. Peru, Ghana and Vietnam are economies where political reforms not only helped in making good progress but also countered the major challenges that arose from sustaining the UHC efforts by addressing fragmentation in financing and service delivery [18].

\section{b1) Securing Sustainable Financing}

Health care is costly. Out-of-pocket payments and financial catastrophe or impoverishment are major financial barriers that prevent people from seeking and receiving needed health services When states adopted the resolution of providing universal coverage, their first huddle was to develop an adequate and sustainable financing mechanism for health services [19]. While low- and middle income countries may first need to increase the amount of their budgets they devote to health [11], other support their health financing pool by revenue collection. Many countries have successfully expanded health coverage through either tax-based systems or compulsory social health insurance systems [20]. These systems vary in institutional and organizational arrangements used to ensure funds are raised, pooled and used to purchase or provide services [19].The evidence for association between implementation of universal coverage either via tax-based funding or social health insurance with its final outcome is equivocal [21]. While goal of expanded coverage systems is to pool resources to share financial risk among participants, there is no one solution for they are embedded in economic, social, and political contexts of the country. Though some countries have now adapted a unique "hybrid systems" that are based on the use of tax revenues but subsidize certain populations maintaining a certain risk pool.

\section{b2) Where It Worked}

France and Japan have reduced overreliance on payroll taxes and have included other forms of tax revenues to sustain UHC [22]. UK's NHS believes in largely tax-based financing to fund universal health care services that are usually free at the point of service [23]. Brazil on the other hand, has resorted to private voluntary health insurance to supplement statutory coverage [24]. Taiwan expanded its narrow tax base by introducing new payroll taxes under a social insurance program [25]. In many LMICs, the hybrid systems may be able to address the challenges and opportunities of private-public partnerships, provided that there are mechanisms for coordination of effort, control of costs, and collaboration of many stakeholders as seen from preliminary evidence in China [26].

Countries are seeking to diversify sources of revenue for UHC, and strategies vary among countries at different stages on the road to UHC. It is the combination of specific rules in revenue collection, pooling and purchasing as well as the 
effectiveness of organizations in implementation determines the efficiency of a health financing system [19]. As for Ghana, is known to manage its single risk pool under its National Health Insurance Law, which redistributes resources from wealthy to poorer households through progressive general taxation on the other hand Japan maintains its multiple risk pools through a combination of standardized benefits and provider payments across plans, subsidies, fund-transfers and equitable distribution [13] [27]. It might be proposed that an integrated risk pool will be advantageous to health financing systems.

c1) Selecting the Right Package of Services

WHO recommends that benefits included in UHC schemes of countries should be comprehensive, prioritize prevention and primary care, and address the diseases most prevalent in the area being considered [28]. Post this initial approach, the inclusion criteria for other health services should be need, mass-opinion, and cost-based. Rational and analytical decisions about these services can be achieved by reviewing mortality-morbidity statistics, cost-benefit analysis, budget-impact analysis, and maximum reduction in out-of-pocket expenditure [29].

c2) Where It Worked

Countries should strive to ease into increased services coverage. In Thailand and Turkey, for example, effective policies included a balanced approach to prioritizing services and medicines for benefits package expansion, strong negotiation with pharmaceutical companies, and the leveraging of provider payment systems so as to bring more benefits to more people [2]. The downside to these choices might be total consumption of budgets and impending financial crises as in Thailand, where meeting the demand for renal replacement consumed nearly $12 \%$ of Thailand's Universal Coverage Scheme budget [30]. Support for the notion of priority setting and opinion-based service choice with rational and analytical approach rises from case studies like India where only $44 \%$ of infants undergo complete vaccination programs but open-heart surgery is subsidized in national public hospitals [31].

d1) Reaching Vulnerable Populations

Identifying and reaching disadvantaged populations and estimating unmet need is another crucial component for UHC systems [32]. Though the global community has included universal health coverage within the Post-2015 Sustainable Development Goals discussion, it must essentially focus on the marginalized as they typically, have worst health outcomes, limited access to healthcare services, pay directly out-of-pocket at the time of care, either ignore or avoid needed care or be impoverished if they seek it. UHC should aim to track the progress of marginalised populations in terms of achieving equitable access, effective coverage and financial risk protection within their own settings [32].

d2) Where It Worked

Japan and some other European countries started their coverage expansions with formal sector workers for ease of taxation and identification [33] but this 
poses a threat of further fragmentation. The quest here is to understand who to reach/coverage, how and still have equitable distribution. Suggested options include equity funds, subsidies for health insurance premiums, health care vouchers, and cash transfers. Oportunidades, Mexico's pioneered initiative provides conditional cash transfers to poor people seeking care from public facilities [34]. The program successfully covers health benefits for 25 million low-income Mexicans (mostly women), with $70 \%$ rural population.

\section{e1) Efficient Use of Resources}

Cost, safety, and availability of resources are key components of sustainable universal health coverage systems for it is a challenge to efficiently using these scarce health resources [2]. It has been documented through health indicators that cost for health services outrun economic inflation in all countries irrespective of their economic standing [35]. WHO reports that most countries fail to 'fully exploit the resources available, whether through poor executed procurement, irrational medicine use, misallocated and mismanaged human and technical resources or fragmented financing and administration' [36]. Another major challenge was production, performance, and distribution of human resource for UHC [2]. An additional paradigm is being considered where efficiency should be sought is a way to design payments so that health care providers deliver appropriate, effective and quality care to patients, without associated incentives to avoid over-treatment [37].

\section{e2) Where It Worked}

In Europe, national decision makers have had to develop strategies to deal with resource scarcity and infrastructure insufficiency along with the controlling the cost of the human resources (e.g. salaries) to ensure universal access to health care and equitable geographical distribution of resources [38]. Piggybacking approaches to intervention delivery and training health workers under various integrative strategies has led to improved performance of UHC in LMIC's like Tanzania and Bangladesh [39]. Taiwan also ensured that it has the organizational ability and human resources to manage a national health insurance scheme before implementing it [40]. It is also important for countries to figure out the most efficient way to design payments so that health care providers deliver high-quality, appropriate, and needed care to patients like China, uses the payment system [41]. It is loosely based on the Medicare's instituted hospital payment method that provided compensation per patient based on the average costs for treating patients with a similar diagnosis [2].

\section{fl) Integrating and Strengthening Health Systems}

Universal health coverage has the potential to provide additional resources for strengthening health systems by establishing integrated and comprehensive healthcare systems. UHC also needs a component of preventive care to deal with communicable diseases and set standards for care which need to be enforced. This is in response to the presence of broken health systems in countries like India with huge gaps in supply and infrastructure, and human resources [42] [43]. 
UHC should serve needs relevant to a nation's population health by strategic alignment of policy and services establishing a continuum of care as seen in Figure 2 [7].

\section{f2) Where It Worked}

Integration of health system is a challenge for most countries firstly due to medical pluralism especially in LMIC's and also to various political and cultural values of a country, which drive the choices undertaken in UHC. For example core features of Canadian health care are enshrined federally, in the Canada Health Act which unified public administration, comprehensiveness, universality, portability, and accessibility. From the patient's standpoint, with exceptions, such as home care, long-term care, dental care, physiotherapy and pharmaceuticals, the system is free of charges for hospital and medical care, thereby approaching the aim of "reasonable access to health services without financial or other barriers". Yet, WHO's landmark study from 2000 of health systems performance in almost 200 countries, ranked the UK in $18^{\text {th }}$ place, Canada in $31^{\text {st }}$ place, and the US (the most expensive health care in the world) in $37^{\text {th }}$ place. Most European countries performed better than Canada [33] especially Thailand which is known to integrate strategies like IMCI (Integrated Management of Childhood Illness) with its IHPP (International Health Policy Program). It is therefore, essential to understand that an integrated or unified system is not always strengthened by its public health setting or is embraced by public policy which is essential for establishing a continuum of care.

\section{A truly "Global" UHC}

Making quality, affordable health services available to an entire population is a

Strategic alignment of policy and services across the continuum of health needs (schematic)

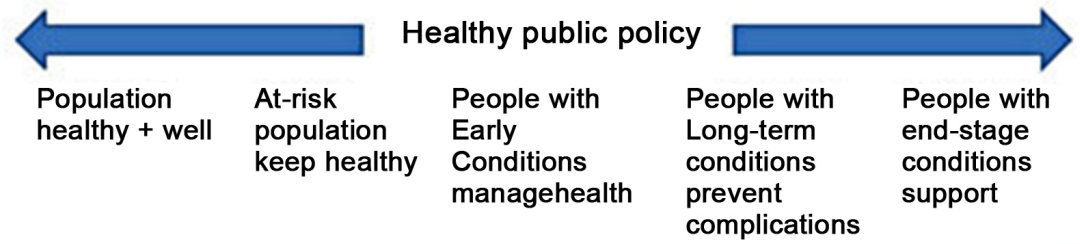

\section{Public health, primary health care and community services}

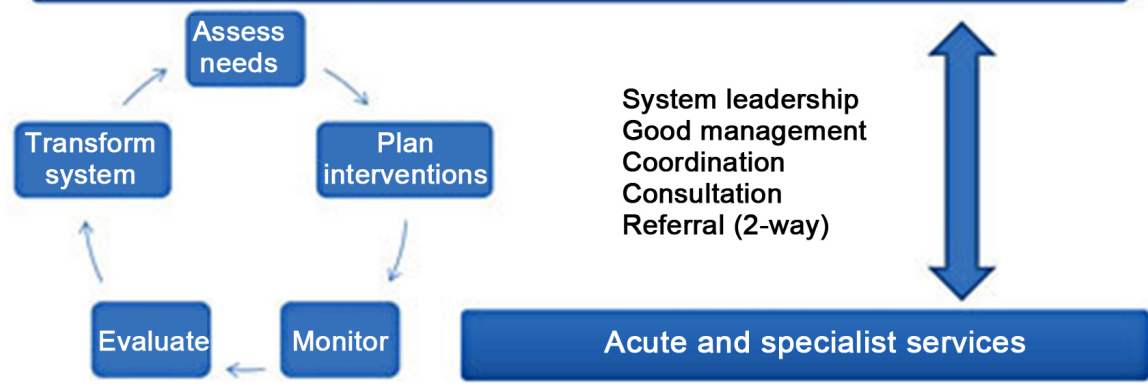

Figure 2. Strategic alignment of policy and services across the continuum of health needs (reproduced [7]). 
difficult undertaking - one that entails a variety of resource and implementation challenges and requires sustained political will [2] [11]. Universal health coverage is still being monitored for is usability. Questions like does it really improve health or establish equity have been countered and answered repeatedly. It has been suggested that broader health coverage generally leads to better access to necessary care and improved population health, particularly for poor people [44]. With each nation facing its own demons, like communicable diseases in Asia and Africa but ageing population in Singapore, equity can be assessed as necessitating the prioritization of those who with the greatest health needs in order to secure for them equality of opportunity or capability to the furthest extent possible, but is difficult to monitor. Also with the US being the industrialized country without some form of universal access to medical services, there is an initiation in the field of UHC with the era of Obamacare. As one size never fits all, neither do the healthcare programs across the world. Studies from high-income countries tend to focus on access to specialised services and procedures such as mental health services, and distinct populations such as children, elderly and psychiatric patients rather than the population as a whole, while LMIC's are still focused on building institutional capacity, learn from the experiences of other countries, and adapt innovative approaches emerging across the globe that can speed up coverage expansion [2] [32]. With 25 wealthiest nations and several middle-income countries, including Brazil, Mexico, and Thailand well in establishing UHC, the main lesson, therefore, is that all nations should learn from one another, especially from those systems which appear to be doing better, and are more prepared to innovate, test and evaluate new approaches.

\section{Conclusion}

UHC is being called the third global health transition; it has emerged as the single most powerful concept that public health has to offer. It is inclusive and sole tool to establish continuum of care by linking strategies to equities. It has the potential to unify services and delivers them in a comprehensive way as seen in France which combines private and public sectors to provide UHC as has received prime rank in doing so or Japan that ranks 10 and runs an employerbased system or through the national health care program. Lessons can also be learnt from UK's NHS for it has been lauded its quality of care, efficiency and low cost at the point of service. These economies have proved that universal coverage is the hallmark of a government's commitment to improve the wellbeing of all its citizens. The whole ideas is to learn lessons from countries with successful health systems and best practices to shape one's own journeys to UHC, making adjustments and adaptations as they build experience. We suggest that the focus should be on the groundwork, which needs to be carefully laid, so the services and facilitates provided under UHC are able to meet the health needs of all being covered by it regardless of how it is being funded, when and 
who paid for it. The concern is that in order for it to be a successful UHC, it should be that these services are accessed by all people when needed. For an effective UHC strategy:

1) Focus on vulnerable groups must be assured.

2) UHC must not be a choice but prioritised involving political forces, bureaucracy and stakeholders alike.

3) Emphasis should be laid on strengthening, the three pillars of UHC systems making it accessible, affordable and a quality product.

4) Eliminate barriers to access and lay its foundations on equity

5) Countries spending less than $3 \%$ of GDP in public expenditure should commit to increase funding by $0.3 \%$ especially for low and middle income countries [45] [46] [47].

6) Foundations for paying for UHC may rise from national funds, but strategies must be designed to include private sector through regulations and partnerships.

7) Establish strict accountabilities and a lucid priority-setting technique to define what will be included in the UHC service package for every country which should be fluid and adaptable [48].

The most important point is whether fundamental equity or should equality be the bedrock of health in country-that everyone should have basic health insurance coverage or a certain vulnerable group should be pushed up the ladder. For decades after countries made a commitment to health, it is a good time to include the rest of the people who remain left out.

\section{Competing Interests}

The authors declare that they have no competing interests.

\section{References}

[1] WHO (2012) What Is Universal Health Coverage. http://www.who.int/features/qa/universal_health_coverage/en/

[2] Maeda, A., et al. (2014) Universal Health Coverage for Inclusive and Sustainable Development: A Synthesis of 11 Country Case Studies. World Bank Publications. https://doi.org/10.1596/978-1-4648-0297-3

[3] Gwatkin, D.R. and Ergo, A. (2011) Universal Health Coverage: Friend or Foe of Health Equity? The Lancet, 377, 2160-2161. https://doi.org/10.1016/S0140-6736(10)62058-2

[4] WHO (2009) UNAIDS, and UNICEF, towards Universal Access: Scaling up Priority HIV/AIDS Interventions in the Health Sector.

[5] UN (2011) United Nations: The Millennium Development Goals Report 2011. UN.

[6] Garrett, L., Chowdhury, A.M.R. and Pablos-Méndez, A. (2009) All for Universal Health Coverage. The Lancet, 374, 1294-1299. https://doi.org/10.1016/S0140-6736(09)61503-8

[7] White, F. (2015) Primary Health Care and Public Health: Foundations of Universal Health Systems. Medical Principles and Practice, 24, 103-116. 
https://doi.org/10.1159/000370197

[8] Sengupta, A. (2013) Universal Health Coverage: Beyond Rhetoric. Municipal Services Project, Occasional Paper No. 2013.

[9] WHO (2010) The World Health Report [2010]: Health Systems Financing; the Path to Universal Coverage. W.H. Organization.

[10] Witter, S., et al. (2017) Minding the Gaps: Health Financing, Universal Health Coverage and Gender. Health Policy and Planning, 32, v4-v12. https://doi.org/10.1093/heapol/czx063

[11] McKee, M., et al. (2013) Universal Health Coverage: A Quest for All Countries but under Threat in Some. Value in Health, 16, S39-S45. https://doi.org/10.1016/j.jval.2012.10.001

[12] Shan, L., et al. (2017) Perceived Challenges to Achieving Universal Health Coverage: A Cross-Sectional Survey of Social Health Insurance Managers/Administrators in China. BMJ Open, 7, e014425. https://doi.org/10.1136/bmjopen-2016-014425

[13] Lagomarsino, G., et al. (2012) Moving towards Universal Health Coverage: Health Insurance Reforms in Nine Developing Countries in Africa and Asia. The Lancet, 380, 933-943. https://doi.org/10.1016/S0140-6736(12)61147-7

[14] Boerma, T., et al. (2014) Monitoring Progress towards Universal Health Coverage at Country and Global Levels. PLoS Medicine, 11, e1001731.

https://doi.org/10.1371/journal.pmed.1001731

[15] Adams, A.M., et al. (2014) Innovation for Universal Health Coverage in Bangladesh: A Call to Action. The Lancet, 382, 2104-2111. https://doi.org/10.1016/S0140-6736(13)62150-9

[16] Hosseinpoor, A.R., et al. (2011) Towards Universal Health Coverage: The Role of Within-Country Wealth-Related Inequality in 28 Countries in Sub-Saharan Africa. Bulletin of the World Health Organization, 89, 881-889. https://doi.org/10.2471/BLT.11.087536

[17] Somanathan, A., Dao, H.L. and Tien, T.V. (2013) Integrating the Poor into Universal Health Coverage in Vietnam.

[18] Littlejohns, P., et al. (2012) Universal Health Coverage and Litigation in Latin America. Journal of Health Organization and Management, 26, 390-406. https://doi.org/10.1108/14777261211239034

[19] Carrin, G., et al. (2008) Universal Coverage of Health Services: Tailoring Its Implementation. Bulletin of the World Health Organization, 86, 857-863. https://doi.org/10.2471/BLT.07.049387

[20] Etienne, C., Asamoa-Baah, A. and Evans, D.B. (2010) Health Systems Financing: The Path to Universal Coverage. World Health Organization.

[21] Mills, A. (2007) Strategies to Achieve Universal Coverage: Are There Lessons from Middle Income Countries? A Literature Review Commissioned by the Health Systems Knowledge Network. University of the Witwatersrand Centre for Health Policy.

[22] Savedoff, W.D., et al. (2012) Political and Economic Aspects of the Transition to Universal Health Coverage. The Lancet, 380, 924-932. https://doi.org/10.1016/S0140-6736(12)61083-6

[23] Light, D.W. (2003) Universal Health Care: Lessons from the British Experience. American Journal of Public Health, 93, 25-30. https://doi.org/10.2105/AJPH.93.1.25

[24] Teixeira, S.M.F., Belmartino, S. and Baris, E. (2000) Reshaping Health Care in Latin America: A Comparative Analysis of Health Care Reform in Argentina, Brazil, and 
Mexico.

[25] Chiang, T.-L. (1997) Taiwan's 1995 Health Care Reform. Health Policy, 39, 225-239. https://doi.org/10.1016/S0168-8510(96)00877-9

[26] Liu, G.G., et al. (2009) The Role of For-Profit Hospitals in Medical Expenditures: Evidence from Aggregate Data in China. China Economic Review, 20, 625-633. https://doi.org/10.1016/j.chieco.2009.06.002

[27] Ikegami, N., et al. (2011) Japanese Universal Health Coverage: Evolution, Achievements, and Challenges. The Lancet, 378, 1106-1115. https://doi.org/10.1016/S0140-6736(11)60828-3

[28] Minh, H.V., et al. (2014) Progress toward Universal Health Coverage in ASEAN.

[29] Getzen, T.E. (2000) Health Care Is an Individual Necessity and a National Luxury: Applying Multilevel Decision Models to the Analysis of Health Care Expenditures. Journal of Health Economics, 19, 259-270. https://doi.org/10.1016/S0167-6296(99)00032-6

[30] Treerutkuarkul, A. (2010) Thailand: Health Care for All, at a Price. Bulletin of the World Health Organization, 88, 84. https://doi.org/10.2471/BLT.10.010210

[31] Glassman, A. and Chalkidou, K. (2012) Priority-Setting in Health: Building Institutions for Smarter Public Spending. Center for Global Development, Washington DC.

[32] Rodney, A.M. and Hill, P.S. (2014) Achieving Equity within Universal Health Coverage: A Narrative Review of Progress and Resources for Measuring Success. International Journal for Equity in Health, 13, 72. https://doi.org/10.1186/s12939-014-0072-8

[33] World Health Organization (2000) The World Health Report 2000: Health Systems Improving Performance.

[34] Yanes, P. (2011) Mexico's Targeted and Conditional Transfers: Between Oportunidades and Rights. Economic \& Political Weekly, 46, 49-54.

[35] OECD (2011) OECD Indicators, Health at a Glance 2011. OECD Indicators. https://doi.org/10.1787/888932525590

[36] Vega, J. (2013) Universal Health Coverage: The Post-2015 Development Agenda. The Lancet, 381, 179-180. https://doi.org/10.1016/S0140-6736(13)60062-8

[37] Christianson, J.B., Leatherman, S.T. and Sutherland, K. (2007) Financial Incentives, Healthcare Providers and Quality Improvements: A Review of the Evidence. The Health Foundation.

[38] Saltman, R.B., Figueras, J. and Sakellarides, C. (1998) Critical Challenges for Health Care Reform in Europe. McGraw-Hill International, New York.

[39] Victora, C.G., et al. (2004) Achieving Universal Coverage with Health Interventions. The Lancet, 364, 1541-1548. https://doi.org/10.1016/S0140-6736(04)17279-6

[40] Lu, J.-F.R. and Hsiao, W.C. (2003) Does Universal Health Insurance Make Health Care Unaffordable? Lessons from Taiwan. Health Affairs, 22, 77-88. https://doi.org/10.1377/hlthaff.22.3.77

[41] Hu, S., et al. (2008) Reform of How Health Care Is Paid for in China: Challenges and Opportunities. The Lancet, 372, 1846-1853. https://doi.org/10.1016/S0140-6736(08)61368-9

[42] Campbell, J., et al. (2013) Human Resources for Health and Universal Health Coverage: Fostering Equity and Effective Coverage. Bulletin of the World Health Organization, 91, 853-863. https://doi.org/10.2471/BLT.13.118729

[43] Jimba, M., et al. (2010) Health Workforce: The Critical Pathway to Universal Health 
Coverage. Background Paper for the Global Symposium on Health Systems Research.

[44] Moreno-Serra, R. and Smith, P.C. (2012) Does Progress towards Universal Health Coverage Improve Population Health? The Lancet, 380, 917-923. https://doi.org/10.1016/S0140-6736(12)61039-3

[45] Marten, R., et al. (2014) An Assessment of Progress towards Universal Health Coverage in Brazil, Russia, India, China, and South Africa (BRICS). The Lancet, 384, 2164-2171. https://doi.org/10.1016/S0140-6736(14)60075-1

[46] Tangcharoensathien, V., Mills, A. and Palu, T. (2015) Accelerating Health Equity: The Key Role of Universal Health Coverage in the Sustainable Development Goals. BMC Medicine, 13, 101. https://doi.org/10.1186/s12916-015-0342-3

[47] Beattie, A., Yates, R. and Noble, D.J. (2016) Accelerating Progress towards Universal Health Coverage in Asia and Pacific: Improving the Future for Women and Children. BMJ Global Health, 1, i12-i18.

[48] Lauer, J.A., Rajan, D. and Bertram, M.Y. (2017) Priority Setting for Universal Health Coverage: We Need to Focus both on Substance and on Process. Comment on "Priority Setting for Universal Health Coverage: We Need Evidence-Informed Deliberative Processes, not Just More Evidence on Cost-Effectiveness". International Journal of Health Policy and Management, 6, 601-603.

https://doi.org/10.15171/ijhpm.2017.06 